\title{
The secondary prophylactic efficacy of beta-blocker af- ter endoscopic gastric variceal obturation for first acute episode of gastric variceal bleeding
}

\author{
Moon Han Choi', Young Seok Kim', Sang Gyune Kim', Yun Nah Lee', Yu Ri Seo', Min Jin Kim', Sae Hwan Lee, Soung \\ Won Jeong ${ }^{2}$, Jae Young Jang ${ }^{2}$, Hong Soo Kim ${ }^{3}$, and Boo Sung Kim ${ }^{1}$ \\ 'Digestive Disease Center and Research Institute, Department of Internal Medicine, Soonchunhyang University Bucheon Hospital, \\ Soonchunhyang University School of Medicine, Bucheon; ${ }^{2}$ Institute for Digestive Research, Department of Internal Medicine, Soonchun- \\ hyang University Seoul Hospital, Soonchunhyang University School of Medicine, Seoul; ${ }^{3}$ Department of Internal Medicine, Soonchunhy- \\ ang University Cheonan Hospital, Soonchunhyang University School of Medicine, Cheonan, Korea
}

Background/Aims: The most appropriate treatment for acute gastric variceal bleeding (GVB) is currently endoscopic gastric variceal obturation (GVO) using Histoacryl ${ }^{\circledR}$. However, the secondary prophylactic efficacy of beta-blocker (BB) after GVO for the first acute episode of GVB has not yet been established. The secondary prophylactic efficacy of BB after GVO for the first acute episode of GVB was evaluated in this study.

Methods: Ninety-three patients at Soonchunhyang University Hospital with acute GVB who received GVO using Histoacryl ${ }^{\circledR}$ were enrolled between June 2001 and March 2010. Among these, 42 patients underwent GVO alone (GVO group) and 51 patients underwent GVO with adjuvant BB therapy (GVO+BB group). This study was intended for patients in whom a desired heart rate was reached. The rates of rebleeding-free survival and overall survival were calculated for the two study groups using Kaplan-Meyer analysis and Cox's proportional-hazards model.

Results: The follow-up period after the initial eradication of gastric varices was $18.14 \pm 25.22$ months (mean $\pm S D$ ). During the follow-up period, rebleeding occurred in 10 (23.8\%) and 21 (41.2\%) GVO and GVO+BB patients, respectively, and 39 patients died [23 (54.8\%) in the GVO group and $16(31.4 \%)$ in the GVO+BB group]. The mean rebleeding-free survival time did not differ significantly between the GVO and GVO+BB groups (65.40 and 37.40 months, respectively; $P=0.774$ ), whereas the mean overall survival time did differ (52.54 and 72.65 months, respectively; $P=0.036$ ).

Conclusions: Adjuvant BB therapy after GVO using Histoacryl ${ }^{\circledR}$ for the first acute episode of GVB could decrease the mortality rate relative to GVO alone. However, adjuvant $\mathrm{BB}$ therapy afforded no benefit for the secondary prevention of rebleeding in GV. (Clin Mol Hepatol 2013;19:280-287)

Keywords: Gastric varices; Beta-blocker; Secondary prevention

\section{Abbreviations:}

BB, beta-blocker; BRTO, balloon-occluded retrograde transvenous obliteration; EV, esophageal varices; EVB, esophageal variceal bleeding; GOV1, type 1 gastro-esophageal varices; GOV2, type 2 gastro-esophageal varices; GV, gastric varices; GVB, gastric variceal bleeding; GVO, gastric variceal obturation; HCC, hepatocelluar carcinoma; IGV1, type 1 isolated gastric varices; MELD score, model for end-stage liver disease score; TIPS, transjugular intrahepatic portosystemic shunt

\section{Corresponding author : Young Seok Kim}

Digestive Disease Center and Research Institute, Department of Internal Medicine, Soonchunhyang University School of Medicine, 170 Jomaru-ro, Wonmi-gu, Bucheon 420-767, Korea

Tel. +82-32-621-6546, Fax. +82-32-621-5080

E-mail; liverkys@schmc.ac.kr 


\section{INTRODUCTION}

Gastric varices (GV) are found in $18-70 \%$ of patients with portal hypertension and less common than esophageal varices (EV). ${ }^{1-4}$ Although gastric variceal bleeding (GVB) has lower incidence (10$36 \%$ ) than esophageal variceal bleeding (EVB), but GVB is generally more severe and is associated with more blood transfusion requirement, higher mortality rate (45-55\%) and higher rebleeding rate (38-89\%) than EVB. ${ }^{5-10}$ GVB is difficult to prevent rebleeding because the hemodynamics of the GV are different from those of the $E V .{ }^{7,11}$ Most of GV are supplied primarily by the left gastric vein and posterior gastric vein. ${ }^{3,4}$ And, GV has a lot of blood flow, developed collateral vessels, unlike EV.

Recently, many treatment modalities for acute GVB and prevention of GV rebleeding were used. ${ }^{12}$ These include endoscopic treatment (gastric variceal obturation; GVO, gastric variceal sclerotherapy, gastric variceal ligation), medical treatment using betablocker (BB), transjugular intrahepatic portosystemic shunt (TIPS), balloon-occluded retrograde transvenous obliteration (BRTO) and liver transplantation. ${ }^{13-17}$ Among these, endoscopic GVO using Histoacryl ${ }^{\circledR}$ (n-butyl-2-cyanoacrylate, B. Braun, Aesculap AG, Tuttlingen, Germany) for acute GVB is the most appropriate treatment. The success rate in controlling acute GVB is $90-100 \%{ }^{18-20}$

Use of BB has been documented to decrease the risk of first bleeding and rebleeding from EV and therefore decrease mortality. And, the addition of BB to endoscopic band ligation increased the efficacy of endoscopy alone in the prevention of rebleeding from $E V .^{21}$ However, the benefit of BB for secondary prophylaxis of GVB after GVO for the first acute GVB has limited evidence. Thus, we evaluated the secondary prophylactic efficacy of BB after GVO for the first acute GVB.

\section{PATIENTS AND METHODS}

\section{Patients}

This study was based on a retrospective analysis of medical record review in multicenter setting. This study targeted the $661 \mathrm{pa-}$ tients diagnosed with GV at the Soonchunhyang University Bucheon, Seoul and Cheonan Hospital from June 2001 and March 2010. Among these, patients who treated in GVO were 113.

Inclusion criteria were as follow: (1) age was between 18 and 80 years old (2) cirrhotic patients with endoscopically proved acute GVB; (3) type 1 gastro-esophageal varices (GOV1) or type 2

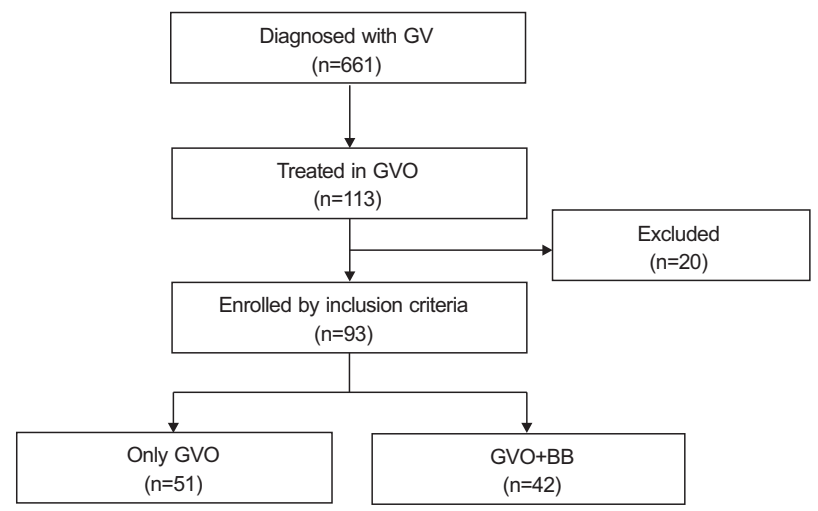

Figure 1. Study flow chart. GV, gastric varices; GVO, gastric variceal obturation; GVO+BB, gastric variceal obturation plus beta-blocker.

gastro-esophageal varices (GOV2) or type 1 isolated gastric varices (IGV 1); (4) GVO for therapeutic purpose within 12 hours of bleeding. ${ }^{12}$

Patients were excluded if they presented with one or more of the followings: (1) association with cerebral vascular accident, uremia, sepsis or other debilitating disease; (2) have a history of previous treatment of $\mathrm{GV}$, including endoscopic therapy, BB, TIPS, or BRTO; (3) have a history of contraindications of $B B$, such as bronchial asthma, severe chronic obstructive pulmonary disease, severe heart failure, atrioventricular block, sinus bradycardia (pulse rate $<55 /$ min) or arterial hypotension (systolic blood pressure $<90$ $\mathrm{mmHg}$ ); (4) did not reduce resting pulse rate up to $25 \%$ or 55 beats per minute; (5) deep jaundice (serum bilirubin $>10 \mathrm{mg} / \mathrm{dL}$ ); (6) hepatorenal syndrome; (7) lack of consent.

Total of 93 patients with the first acute GVB were enrolled consecutively. Two groups of patients who became hemodynamically stable for 3-5 days after initial GVO for the first GVB were compared: Group GVO included 42 patients who underwent only GVO; Group GVO+BB included 51 patients who also underwent GVO and additional BB therapy (Fig. 1).

\section{Technique of endoscopic Histoacryl ${ }^{\circledR}$ injection}

An endoscopist with experience of more than 5 years performed Histoacryl ${ }^{\circledR}$ injection. The endoscopic Histoacryl ${ }^{\circledR}$ injection was performed using a GIF-H260 or GIF-XQ240 endoscope (Olympus Co., Tokyo, Japan) and 7 French injection needle catheter (MTW Endoskopie, Wesel, Germany). Usually $1 \mathrm{~mL}$ of a 1:1 mixture of 0.5 $\mathrm{mL}$ Histoacryl ${ }^{\circledR}$ and equal volume of lipiodol (Guerbet GmbH, Sulzbach, Germany) was administered per injection. The injection needle catheter was advanced through the endoscope into the stom- 
ach, and then inserted directly into the GV. After injection, the location of lipiodol in the GV was identified using fluoroscopy. After that, the injection needle catheter was flushed with sterile water. Histoacryl ${ }^{\circledR}$ injections were repeated until GV appeared to be completely obliterated in one session. If a second session was considered to be necessary, it was done within one week of the initial session. If the GV was not completely obturated, Histoacryl ${ }^{\circledR}$ was reinjected until all the GV became solidified.

\section{Beta-blocker therapy}

Propranolol was started at a dose of $20 \mathrm{mg}$, twice daily as soon as hemodynamic stability was achieved after GVO. The dose of propranolol was increased by $20 \mathrm{mg}$ every 3-5 days, if the target dose was not reached. Propranolol was adjusted according to the dosage that reduced resting pulse rate up to $25 \%$ or 55 beats per minute or reached to the maximal dose of $80 \mathrm{mg} /$ day if the medication was well tolerated and the systolic blood pressure was $>$ $90 \mathrm{mmHg}$. The compliance was assessed by reduction of pulse rate or by quantifying the amount of tablets consumed.

\section{Definitions}

The classification of GV was described by Sarin et al ${ }^{3}$. GOV1 is a continuation of $\mathrm{EV}$ and extend for 2 to $5 \mathrm{~cm}$ below from the gastroesophageal junction along the lesser curvature side of the stomach, GOV2 is a continuation of EV and extend into the fundus. IGV1 is a GV in the absence of EV and the isolated GV located in the fundus of the stomach. The form of GV was classified into three types by Hashizume et al tortuous (F1), nodular (F2), and tumorous (F3). ${ }^{7}$

The severity of cirrhosis was classified according to Child-Pugh score and model for end-stage liver disease (MELD) score. 22,23

Rebleeding of GV was defined as hematemesis: vomitus of red blood or coffee grounds material, melena: black, tarry, foul-smelling stool, hematochezia: passage of bright red or maroon blood from the rectum, or death within 6 weeks after endoscopic Histoacryl ${ }^{\circledR}$ injection. ${ }^{12}$ The primary end point was rebleeding-free survival and the secondary end point was overall survival.

\section{Statistical analysis}

Results were expressed as mean \pm SD for continuous variables and as numbers (percentage) for categorical variables. Analysis was performed using the independent $t$-test or $\chi^{2}$ test for continuous variables and Chi-square analysis or Fisher's exact test for categorical variables. Rebleeding-free survival and overall survival were expressed using the Kaplan-Meier analysis and compared by

Table 1. Baseline clinical characteristics of patients with gastric variceal bleeding

\begin{tabular}{|c|c|c|c|}
\hline N or mean $\pm S D$ & GVO (n=42) & GVO+BB $(n=51)$ & $P$-value \\
\hline Age (yr) & $58.62 \pm 10.99$ & $56.33 \pm 11.79$ & 0.337 \\
\hline $\operatorname{Sex}(M / F)$ & $27 / 15$ & $42 / 9$ & 0.048 \\
\hline Etiology of portal hypertension (alcohol/B/C/others) & $17 / 14 / 3 / 8$ & $23 / 20 / 2 / 6$ & 0.662 \\
\hline Esophageal varices $(-/+)$ & $11 / 31$ & $8 / 43$ & 0.211 \\
\hline Ascites (-/easily/poorly controlled) & 19/12/11 & $18 / 24 / 9$ & 0.184 \\
\hline Hepatic encephalopathy (-/grade 1-2/grade 3-4) & $36 / 3 / 3$ & $41 / 7 / 3$ & 0.588 \\
\hline Albumin (g/dL) & $2.76 \pm 0.65$ & $2.96 \pm 0.50$ & 0.111 \\
\hline Total bilirubin (mg/dL) & $2.86 \pm 4.35$ & $2.36 \pm 3.37$ & 0.545 \\
\hline Creatinine (mg/dL) & $1.04 \pm 0.52$ & $0.86 \pm 0.27$ & 0.049 \\
\hline Prothrombin time (INR) & $1.62 \pm 0.63$ & $1.48 \pm 0.31$ & 0.172 \\
\hline Platelet $\left(/ \mathrm{mm}^{3}\right)$ & $111,520 \pm 72,903$ & $108,630 \pm 67,566$ & 0.844 \\
\hline Child-Pugh score & $8.33 \pm 2.563$ & $8.04 \pm 1.969$ & 0.544 \\
\hline MELD score & $13.98 \pm 6.8$ & $13.22 \pm 4.7$ & 0.542 \\
\hline Type (GOV1/GOV2/IGV1) & $15 / 20 / 7$ & 28/19/4 & 0.139 \\
\hline Form of GV (F1/F2/F3) & $4 / 9 / 29$ & $2 / 15 / 34$ & 0.426 \\
\hline
\end{tabular}

GVO, gastric variceal obturation; BB, beta-blocker; B, chronic hepatitis B; C, chronic hepatitis C; INR, International normalized ratio; MELD, model for end-stage liver disease, GOV1, type 1 gastro-esophageal varices; GOV2, type 2 gastro-esophageal varices; IGV1, type 1 isolated gastric varices. 
Cox's proportional hazards model. $P$-value of $<0.05$ was considered significant. Statistical analysis was done using the Statistical Package for Social Sciences (SPSS 18.0 for Windows, SPSS Inc., Chicago, IL, USA).

\section{RESULTS}

\section{Baseline clinical characteristics}

Total of 93 patients with first acute GVB were enrolled. The 42 and 51 patients were included in Group GVO and GVO+BB, respectively. The mean follow-up periods after an initial eradication of GV were $18.14 \pm 25.22$ months. The baseline clinical characteristics are shown in Table 1. There was no significant difference between Group GVO and GVO+BB in age, etiology of portal hypertension, liver function reserve, classification and form of GV.

\section{Hemodynamic outcomes}

In all patients of Group GVO+BB, the desired heart rate that reduced resting pulse rate up to $25 \%$ or 55 beats per minute could be achieved. The mean dose of propranolol was $47 \pm 16 \mathrm{mg}$ (20-80 $\mathrm{mg}$ ). After propranolol adding therapy, the heart rate was decreased more in Group GVO+BB than Group GVO $(25.3 \pm 12.4$ vs. $4.3 \pm 9.3$ beats per minute, $P=0.001)$. Also, for follow-up period, the heart rate in Group GVO+BB was lower than that in Group GVO (53.4 \pm 10.6 vs. $75.4 \pm 11.3$ beats per minute, $P=0.001)$.

Table 2. Rebleeding and mortality in patients with gastric variceal bleeding

\begin{tabular}{lccc}
\hline & GVO $(\mathbf{n}=\mathbf{4 2})$ & GVO+BB $(\mathbf{n}=\mathbf{5 1})$ & $\boldsymbol{P}$-value \\
\hline Rebleeding, no (\%) & $10(23.8)$ & $21(41.2)$ & 0.076 \\
GVB & 9 & 11 & \\
\hline EVB & 1 & 8 & \\
\hline PUB & 0 & 2 & \\
\hline Death, no (\%) & $23(54.8)$ & $16(31.4)$ & 0.032 \\
\hline GVB & 10 & 2 & \\
\hline EVB & 3 & 6 & \\
\hline HCC & 4 & 3 & \\
\hline Other & 6 & 5 & \\
\hline
\end{tabular}

GVO, gastric variceal obturation; $B B$, beta-blocker; GVB, gastric variceal bleeding; EVB, esophageal variceal bleeding; PUB, peptic ulcer bleeding; HCC, hepatocellular carcinoma.

"Sepsis, 5; hepatorenal syndrome, 4; acute myocardial infarction, 1; laryngeal cancer, 1.

\section{Hemostatic outcomes and mortality}

The mean volume of Histoacry ${ }^{\circledR}$ administered was $2.1 \pm 0.9 \mathrm{~mL}$. The mean number of sessions were $1.4 \pm 0.5$. No treatment-related complications were noted.

The hemostatic outcomes and mortality are shown in Table 2. During follow-up period, rebleeding occurred in 10 patients (23.8\%) and 21 patients (41.2\%) in Group GVO and GVO+BB, re-

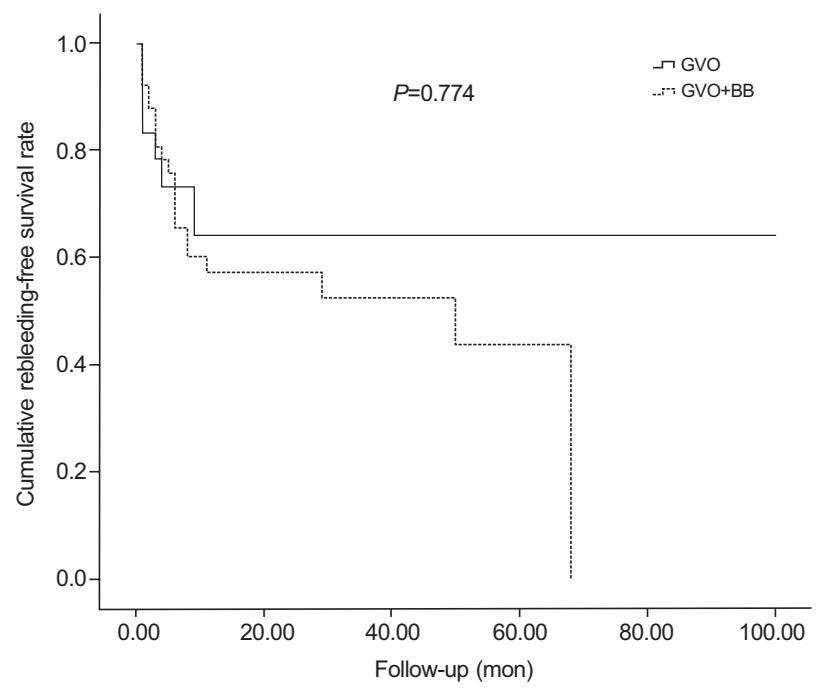

Figure 2. Rebleeding-free survival rate in patients with gastric variceal bleeding.

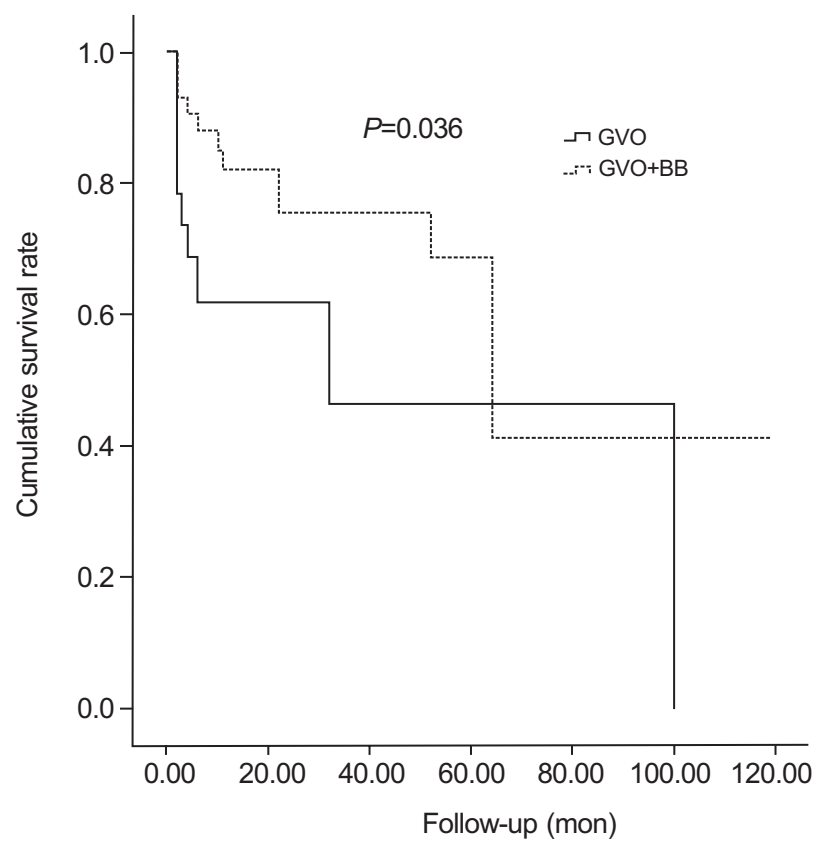

Figure 3. Overall survival rate in patients with gastric variceal bleeding. 
spectively. The most common rebleeding source in two groups was GV. The mean rebleeding-free survival times were 65.40 and 37.40 months, respectively, and were not different significantly ( $P=0.774)$ (Fig. 2).

In follow-up period, 23 patients (54.8\%) died in Group GVO. In
Group GVO+BB, 16 patients (31.4\%) died. The causes of death were GVB (12), EVB (9), hepatocellular carcinoma (HCC) (7), sepsis (5), hepatorenal syndrome (4), acute myocardial infarction (1) and laryngeal cancer (1). The mean overall survival times were 52.54 and 72.65 months, respectively, and there were significant differ-

Table 3. Univariate and multivariate analysis of rebleeding in patients with gastric variceal bleeding

\begin{tabular}{|c|c|c|c|c|}
\hline & \multicolumn{2}{|c|}{ Univariate analysis } & \multicolumn{2}{|c|}{ Multivariate analysis } \\
\hline & Hazard ratio & $P$-value & Hazard ratio & $P$-value \\
\hline BB & & 0.781 & & \\
\hline- & 1.000 & & & \\
\hline+ & $1.115(0.517-2.403)$ & & & \\
\hline Age (yr) & $0.978(0.946-1.010)$ & 0.177 & & \\
\hline Etiology of portal hypertension & & 0.567 & & \\
\hline Alcohol & 1.000 & & & \\
\hline B & $1.332(0.596-2.977)$ & & & \\
\hline C & 1.000 & & & \\
\hline Other & $2.065(0.759-5.617)$ & & & \\
\hline Esophageal varices & & 0.117 & & \\
\hline- & 1.000 & & & \\
\hline+ & $2.596(0.786-8.567)$ & & & \\
\hline Ascites & & 0.070 & & \\
\hline- & 1.000 & & & \\
\hline+ & $2.191(0.937-5.120)$ & & & \\
\hline Hepatic encephalopathy & & 0.272 & & \\
\hline- & 1.000 & & & \\
\hline+ & $1.662(0.672-4.109)$ & & & \\
\hline Albumin (g/dL) & $0.510(0.280-0.927)$ & 0.027 & $0.735(0.344-1.569)$ & 0.426 \\
\hline Total bilirubin (mg/dL) & $1.090(1.014-1.172)$ & 0.019 & $1.015(0.890-1.158)$ & 0.821 \\
\hline Creatinine $(\mathrm{mg} / \mathrm{dL})$ & $1.075(0.424-2.726)$ & 0.878 & & \\
\hline Prothrombin time (INR) & 2.115 (1.216-3.679) & 0.008 & $0.926(0.372-2.308)$ & 0.926 \\
\hline Platelet $\left(/ \mathrm{mm}^{3}\right)$ & $0.996(0.990-1.002)$ & 0.235 & & \\
\hline Child-Pugh score & $1.272(1.099-1.474)$ & 0.001 & $1.120(0.857-1.464)$ & 0.012 \\
\hline MELD score & $1.092(1.035-1.153)$ & 0.001 & 1.054 (0.971-1.145) & 0.208 \\
\hline Type & & 0.150 & & \\
\hline GOV1 & 1.000 & & & \\
\hline GOV2 & $1.548(0.750-3.193)$ & & & \\
\hline IGV1 & $0.257(0.034-1.963)$ & & & \\
\hline Form of GV & & 0.902 & & \\
\hline F1 & 1.000 & & & \\
\hline F2 & $0.721(0.153-3.385)$ & & & \\
\hline F3 & $0.822(0.192-3.529)$ & & & \\
\hline
\end{tabular}

BB, beta-blocker; B, chronic hepatitis B; C, chronic hepatitis C; INR, International normalized ratio; MELD, model for end-stage liver disease, GOV1, type 1 gastro-esophageal varices; GOV2, type 2 gastro-esophageal varices; IGV1, type 1 isolated gastric varices. 
Table 4. Univariate and multivariate analyses of overall survival in patients with gastric variceal bleeding

\begin{tabular}{|c|c|c|c|c|}
\hline & \multicolumn{2}{|c|}{ Univariate analysis } & \multicolumn{2}{|c|}{ Multivariate analysis } \\
\hline & Hazard ratio & $P$-value & Hazard ratio & $P$-value \\
\hline BB & & 0.002 & & 0.003 \\
\hline- & 1.000 & & 1.000 & \\
\hline+ & $0.346(0.179-0.671)$ & & $0.331(0.159-0.687)$ & \\
\hline Age (yr) & 1.016 (0.989-1.045) & 0.246 & & \\
\hline Etiology of portal hypertension & & 0.096 & & \\
\hline Alcohol & 1.000 & & & \\
\hline $\mathrm{B}$ & $0.442(0.173-1.125)$ & & & \\
\hline C & $0.581(0.232-1.455)$ & & & \\
\hline Other & $1.604(0.469-5.487)$ & & & \\
\hline Esophageal varices & & 0.838 & & \\
\hline- & 1.000 & & & \\
\hline+ & $1.090(0.477-2.489)$ & & & \\
\hline Ascites & & 0.142 & & \\
\hline- & 1.000 & & & \\
\hline+ & $1.690(0.838-3.407)$ & & & \\
\hline Hepatic encephalopathy & & $<0.001$ & & 0.019 \\
\hline- & 1.000 & & 1.000 & \\
\hline+ & $3.696(1.847-7.395)$ & & 3.631 (1.232-10.703) & \\
\hline Albumin (g/dL) & $0.281(0.156-0.505)$ & $<0.001$ & $0.340(0.156-0.743)$ & 0.007 \\
\hline Total bilirubin (mg/dL) & $1.106(1.047-1.167)$ & $<0.001$ & $1.086(0.991-1.190)$ & 0.078 \\
\hline Creatinine (mg/dL) & $1.616(0.774-3.373)$ & 0.201 & & \\
\hline Prothrombin time (INR) & $2.025(1.227-3.339)$ & 0.006 & $0.496(0.219-1.126)$ & 0.094 \\
\hline Platelet $\left(/ \mathrm{mm}^{3}\right)$ & 1.002 (0.997-1.006) & 0.494 & & \\
\hline Child-Pugh score & $1.335(1.171-1.521)$ & $<0.001$ & $0.994(0.748-1.321)$ & 0.013 \\
\hline MELD score & $1.080(1.030-1.133)$ & 0.002 & 1.025 (0.944-1.113) & 0.021 \\
\hline Type & & 0.740 & & \\
\hline GOV1 & 1.000 & & & \\
\hline GOV2 & $0.972(0.502-1.884)$ & & & \\
\hline IGV1 & $0.620(0.184-2.094)$ & & & \\
\hline Form of GV & & 0.484 & & \\
\hline F1 & 1.000 & & & \\
\hline $\mathrm{F} 2$ & $0.479(0.128-1.798)$ & & & \\
\hline F3 & $0.692(0.209-2.294)$ & & & \\
\hline Rebleeding & & 0.979 & & \\
\hline- & 1.000 & & & \\
\hline+ & $1.009(0.518-1.966)$ & & & \\
\hline
\end{tabular}

BB, beta-blocker; B, chronic hepatitis B; C, chronic hepatitis C; INR, International normalized ratio; MELD, model for end-stage liver disease, GOV1, type 1 gastro-esophageal varices; GOV2, type 2 gastro-esophageal varices; IGV1, type 1 isolated gastric varices. 
ences between two groups ( $P=0.036)$ (Fig. 3).

\section{Factors associated with rebleeding and overall survival}

Univariate analysis showed that albumin, total bilirubin, prothrombin time, Child-Pugh score and MELD score were associated with higher incidence of rebleeding (Table 3). On multivariate analysis, Child-Pugh score was an independent determinant of rebleeding. Univariate analysis showed that BB, hepatic encephalopathy, albumin, total bilirubin, prothrombin time, Child-Pugh score and MELD score were associated with higher mortality (Table 4). On multivariate analysis, BB, hepatic encephalopathy, albumin, Child-Pugh score and MELD score were independent determinants of overall survival.

\section{DISCUSSION}

The endoscopic GVO using Histoacryl ${ }^{\circledR}$ has been used successfully to control bleeding from GV since the first report in 1986 by Soehendra et al $^{13}$ Histoacryl ${ }^{\circledR}$ based tissue adhesive, was employed as a nonsuture method for closing wounds in surgery for a long time. Histoacry ${ }^{\circledR}$ in monomer form polymerizes rapidly in presence of ionic substances like moisture, blood or tissue fluid. Polymerized form has excellent tensile strength and is very effective in embolization of GVB. But, endoscopic GVO using Histoacry ${ }^{\circledR}$ sometimes has complications such as systemic embolism, septicemia, or damage by endoscope. 24,25

Recently, many studies show that GVO is more effective and safer than endoscopic gastric variceal sclerotherapy and ligation in the management of acute GVB. ${ }^{26-29}$ Also, Mahadeva et al have reported that GVO was more cost effective than TIPS in the management of acute GVB. ${ }^{30}$ BRTO has a high hemostasis rate and rebleeding prevention rate of GV, but has limitation that it can be used only in patients with gastrorenal shunt. ${ }^{17}$ Thus, endoscopic GVO using Histoacryl ${ }^{\circledR}$ is recommended as the initial treatment of acute GVB. However, the best therapy for the secondary prevention of GVB is still not satisfactory.

Mishra et al have reported that BB therapy alone is not as effective as GVO in preventing rebleeding of GV. ${ }^{31}$ GVO is more effective than BB therapy for the prevention of rebleeding of GV and improving survival. However, the role of BB in addition to GVO is uncertain. Therefore, this study was designed to evaluate that the BB adding therapy after endoscopic GVO using Histoacryl ${ }^{\circledR}$ for the first acute GVB can prove better benefit in preventing rebleeding of GVB and in reducing mortality.

Generally, it is known that the BB adding therapy after GVO is not better than GVO therapy alone in preventing rebleeding of GVB. Because, BB prevent variceal bleeding due to reduce portal pressure. However, portal pressure is lower in GVB patients than in EVB patients. Thus, portal pressure may not be so critical in GVB patients. ${ }^{7,11}$ And, many patients with GV already have a gastrorenal shunt, therefore BB may not be as effective as in patients with EV. ${ }^{5,11}$ Actually, this study showed that the BB adding therapy after GVO had no benefit for the prevention of rebleeding of GVB. But, the major limitation of this study is that we did not measure hepatic venous pressure gradient. Also, this study showed that rebleeding of $\mathrm{EV}$ was a relatively large number in group $\mathrm{GVO}+\mathrm{BB}$ than in group GVO. This suggests that patients with GV and severe $\mathrm{EV}$ are more likely to have been taking a BB. However, this study is retrospective study. Thus, a larger-scale randomized controlled trial is required to evaluate BB effect for prevention of rebleeding in patients with GVB.

The BB adding therapy after GVO for the first GVB could decrease mortality, as compared with GVO alone. We thought that Group GVO has more patients with HCC or other cause of death than Group GVO+BB. Also, among the many related factors, the Child-Pugh score and MELD score were significantly associated with mortality. Kim et al have reported that the Child-Pugh score and MELD score contributed to predicting survival of the patients with GVB. ${ }^{29,32}$ This suggests that important factors in predicting the prognosis of GVB are the severity of cirrhosis.

\section{Conflicts of Interest}

The authors have no conflicts to disclose.

\section{REFERENCES}

1. Sarin SK, Kumar A. Gastric varices: profile, classification, and management. Am J Gastroenterol 1989;84:1244-1249.

2. Greig JD, Garden OJ, Anderson JR, Carter DC. Management of gastric variceal haemorrhage. Br J Surg 1990;77:297-299.

3. Sarin SK, Lahoti D, Saxena SP, Murthy NS, Makwana UK. Prevalence, classification and natural history of gastric varices: a longterm follow-up study in 568 portal hypertension patients. Hepatology 1992;16:1343-1349.

4. Hashizume M, Sugimachi K. Classification of gastric lesions associated with portal hypertension. J Gastroenterol Hepatol 
1995;10:339-343.

5. Ohnishi K, Saito M, Sato S, Nakayama T, Takashi M, lida S, et al. Direction of splenic venous flow assessed by pulsed Doppler flowmetry in patients with a large splenorenal shunt. Relation to spontaneous hepatic encephalopathy. Gastroenterology 1985;89:180-185.

6. Trudeau W, Prindiville T. Endoscopic injection sclerosis in bleeding gastric varices. Gastrointest Endosc 1986;32:264-268.

7. Watanabe K, Kimura K, Matsutani S, Ohto M, Okuda K. Portal hemodynamics in patients with gastric varices. A study in 230 patients with esophageal and/or gastric varices using portal vein catheterization. Gastroenterology 1988;95:434-440.

8. Thakeb F, Salem SA, Abdallah M, el Batanouny M. Endoscopic diagnosis of gastric varices. Endoscopy 1994;26:287-291.

9. Arakawa M, Masuzaki T, Okuda K. Pathomorphology of esophageal and gastric varices. Semin Liver Dis 2002;22:73-82.

10. Ryan BM, Stockbrugger RW, Ryan JM. A pathophysiologic, gastroenterologic, and radiologic approach to the management of gastric varices. Gastroenterology 2004;126:1175-1189.

11. D'Amico G, Pagliaro L, Bosch J. The treatment of portal hypertension: a meta-analytic review. Hepatology 1995;22:332-354.

12. de Franchis $R$, Baveno $V$ Faculty. Revising consensus in portal hypertension: report of the Baveno $V$ consensus workshop on methodology of diagnosis and therapy in portal hypertension. J Hepatol 2010;53:762-768.

13. Soehendra N, Nam VC, Grimm H, Kempeneers I. Endoscopic obliteration of large esophagogastric varices with bucrylate. Endoscopy 1986;18:25-26.

14. Sarin SK, Sachdev G, Nanda R, Misra SP, Broor SL. Endoscopic sclerotherapy in the treatment of gastric varices. $\mathrm{Br} J$ Surg 1988:75:747-750.

15. Shiha G, El-Sayed SS. Gastric variceal ligation: a new technique. Gastrointest Endosc 1999:49:437-441.

16. Rossle M, Richter G, Noldge G, Haag K, Wenz W, Gerck W, et al. Performance of an intrahepatic portacaval shunt (PCS) using a catheter technique: a case report. [Abstract]. Hepatology 1988;8:1348.

17. Kanagawa H, Mima S, Kouyama H, Gotoh K, Uchida T, Okuda K. Treatment of gastric fundal varices by balloon-occluded retrograde transvenous obliteration. J Gastroenterol Hepatol 1996;11:51-58.

18. Huang YH, Yeh $\mathrm{HZ}$, Chen GH, Chang CS, Wu CY, Poon SK, et al. Endoscopic treatment of bleeding gastric varices by N-butyl-2cyanoacrylate (Histoacryl) injection: long-term efficacy and safety. Gastrointest Endosc 2000;52:160-167.

19. Akahoshi T, Hashizume M, Shimabukuro R, Tanoue K, Tomikawa M, Okita $K$, et al. Long-term results of endoscopic Histoacryl injection sclerotherapy for gastric variceal bleeding: a 10-year experience. Surgery 2002;131(Suppl):S176-S181.

20. Joo HS, Jang JY, Eun SH, Kim SK, Jung IS, Ryu CB, et al. Long-term results of endoscopic histoacryl (N-butyl-2-cyanoacrylate) injection for treatment of gastric varices-A 10-year experience. Korean J Gastroenterol 2007:49:320-326.

21. Gonzalez R, Zamora J, Gomez-Camarero J, Molinero LM, Banares $R$, Albillos A. Meta-analysis: Combination endoscopic and drug therapy to prevent variceal rebleeding in cirrhosis. Ann Intern Med 2008;149:109-122.

22. Pugh RN, Murray-Lyon IM, Dawson JL, Pietroni MC, Williams R. Transection of the oesophagus for bleeding oesophageal varices. $\mathrm{Br}$ J Surg 1973;60:646-649.

23. Kamath PS, Wiesner RH, Malinchoc M, Kremers W, Therneau TM, Kosberg $\mathrm{CL}$, et al. A model to predict survival in patients with endstage liver disease. Hepatology 2001;33:464-470.

24. Hwang SS, Kim HH, Park SH, Kim SE, Jung IJ, Ahn BY, et al. N-butyl2-cyanoacrylate pulmonary embolism after endoscopic injection sclerotherapy for gastric variceal bleeding. J Comput Assist Tomogr 2001;25:16-22.

25. Tan YM, Goh KL, Kamarulzaman A, Tan PS, Ranjeev P, Salem O, et al. Multiple systemic embolisms with septicemia after gastric variceal obliteration with cyanoacrylate. Gastrointest Endosc 2002; $55: 276-278$.

26. Jutabha R, Jensen DM, Egan J, Machicado GA, Hirabayashi K. Randomized, prospective study of cyanoacrylate injection, sclerotherapy, or rubber band ligation for endoscopic hemostasis of bleeding canine gastric varices. Gastrointest Endosc 1995;41:201-205.

27. Sarin SK, Jain AK, Jain M, Gupta R. A randomized controlled trial of cyanoacrylate versus alcohol injection in patients with isolated fundic varices. Am J Gastroenterol 2002;97:1010-1015.

28. Lo GH, Lai KH, Cheng JS, Chen MH, Chiang HT. A prospective, randomized trial of butyl cyanoacrylate injection versus band ligation in the management of bleeding gastric varices. Hepatology 2001;33:1060-1064.

29. Kim MY, Um SH, Baik SK, Seo YS, Park SY, Lee Jl, et al. Clinical features and outcomes of gastric variceal bleeding: retrospective Korean multicenter data. Clin Mol Hepatol 2013;19:36-44.

30. Mahadeva S, Bellamy MC, Kessel D, Davies MH, Millson CE. Costeffectiveness of $\mathrm{N}$-butyl-2-cyanoacrylate (histoacryl) glue injections versus transjugular intrahepatic portosystemic shunt in the management of acute gastric variceal bleeding. Am J Gastroenterol 2003;98:2688-2693.

31. Mishra SR, Chander Sharma B, Kumar A, Sarin SK. Endoscopic cyanoacrylate injection versus beta-blocker for secondary prophylaxis of gastric variceal bleed: a randomised controlled trial. Gut 2010;59:729-735.

32. Kim JW, Baik SK, Kim KH, Kim HJ, Jo KW, Hong JH, et al. Effect of endoscopic sclerotherapy using $\mathrm{N}$-butyl-2-cyanoacrylate in patients with gastric variceal bleeding. Korean J Hepatol 2006;12:394-403. 